\title{
Complex approach to transport infrastructure of Arctic region calculations
}

\author{
Vladimir Ulitsky ${ }^{1}$, and Elena Gorodnova ${ }^{1, *}$ \\ ${ }^{1}$ Emperor Alexander I St. Petersburg State Transport University, 9 Moskovsky pr., Saint Petersburg, \\ 190031, Russia
}

\begin{abstract}
At present experts of «Base and Foundation» department of St. Petersburg Transport University do research work and design projects for transport infrastructure objects. Numerical calculation of subsoil in northern ports of Sabbeta and Tanalau settlements in Russian Arctic region is one of these successfully fulfilled projects. Specific features of these ports are the following: to construct building foundations and road embankments on permafrost soils, to predict functioning of compound sea berths and river piers when super heavy arctic vessels transport liquefied gas along the Northern sea route. Numerical calculation allowed defining soil thawing zone under the northern ports' structures. Experience of experts permitted to choose the best solutions to preserve natural soil structure and exclude uneven deformations, which destroy objects and complicate roads functioning in permafrost zone.
\end{abstract}

\section{Introduction}

Due to rapidly increasing loads, dynamic and vibration impact, rising temperatures in frozen soils, structurally unstable soils sharply reduce their strength or completely collapse. These facts being considered, appropriate measures to ensure stability of buildings and structures on these soils are worked out.

A set of special measures include:

1. Negative impact on soils exclusion.

2. Artificial improvement of subsoil structural properties.

3. Constructive measures to decrease buildings' sensibility to uneven deformations of subsoil.

4. Special types of foundation application.

Permafrost soils peculiarity is their properties essential dependence on soils' composition and humidity and also on their temperature. Thus, deformations may occur at frozen soils thawing, and frost heaving - at soils freezing [1]. The First principle of construction on permafrost soils assumes preservation of building subsoil in frozen state both within the period of construction and the entire period of its maintenance. To preserve subsoil in permafrost state various methods are used: 1. Embankment - artificial sand layer - at vertical design of territories or under separate buildings;

\footnotetext{
*Corresponding author: elena.gorodnova@mail.ru
} 
2. Thermo insulation - for structures that occupy small area;

3. Ventilated cellars - the main and the most common way to regulate thermal impact of buildings on subsoil constant temperature, open cellars have contact with external environment.

4. Embankments with air cooling pipes are used mainly in thermo emitting buildings of considerable dimensions in the design. Pipes are laid within the artificial sand layer and taken out of building's walls or to the cellar. Foundation cooling is accomplished by outside cold air distribution in the pipes.

5. Freezing systems are used for preconstruction freezing of subsoil, and also for further maintenance of subsoil constant temperature.

The Second principle of construction assumes that preliminary thawed soils or the soils, thawing within the period of buildings and structures' maintenance, are used as their subsoil.

1. Preconstruction thawing. Heating with electric osmosis and wellpoint groundwater reduction is often applied to increase soil temperature. Thawing is performed both within the limits of entire building area and under separate foundations, in case it is justified by deformations' calculation.

2. Soil thawing during structures' maintenance should be performed with great care, provided by thorough calculation of constant temperature condition of thawing subsoil deformations.

To develop the Payakh and North-Payakh fields, when design documentation of Tanalau oil terminal was working out, thermal impact of the seaport designed structures on frozen soil condition was calculated. As a result, some adjustments to the design were recommended. Problems to define necessity of soils thermal stabilization within the period of construction and maintenance of the facility were solved and geotechnical monitoring programme was developed.

\section{Constructive solutions}

Technical solutions' analysis, thermo engineering calculations and predictive modelling of soil behaviour, depending on engineering-geological, hydrological and geocryological conditions, with facility features consideration, were performed for the following buildings and structures:

- river pier structures

- river bank retaining walls

- buildings and structures on pile foundations with ventilated cellar and without it, excavated facilities of drainage and pumping station (DPS) and water intake.

Design solutions for buildings on pile foundations are presented in Table 1.

Table 1. Design solutions for buildings on pile foundations.

\begin{tabular}{|c|l|c|c|l|}
\hline No & \multicolumn{1}{|c|}{ Type of building } & $\begin{array}{c}\text { Dimensions in the } \\
\text { design }\end{array}$ & $\begin{array}{c}\text { Heating } \\
\text { availability }\end{array}$ & $\begin{array}{c}\text { Technical solutions details in the } \\
\text { underground part of building }\end{array}$ \\
\hline 1 & $\begin{array}{l}\text { Administrative building } \\
\text { with a canteen, 3 floors }\end{array}$ & $\begin{array}{c}18.0 \times 54.0 \\
\text { Height of the floor }- \\
4.2 \mathrm{~m}\end{array}$ & $\begin{array}{c}20^{\circ} \mathrm{C} \\
\text { heated }\end{array}$ & $\begin{array}{l}\text { Open cold ventilated cellar with height } \\
1.4 \mathrm{~m} \text {. Pile foundations. }\end{array}$ \\
\hline 2 & $\begin{array}{l}\text { Building for technical } \\
\text { purposes to store special } \\
\text { equipment }\end{array}$ & $\begin{array}{c}15.0 \times 27.0 \\
\text { With varied height } \\
5.1 \mathrm{~m} \text { and } 7.2 \mathrm{~m}\end{array}$ & $\begin{array}{c}20^{\circ} \mathrm{C} \\
\text { heated }\end{array}$ & $\begin{array}{l}\text { Without a cellar, pile foundations and } \\
\text { raft pile foundations. For soil freezing } \\
\text { the design provides thermo insulation } \\
\text { and piping within foundations and blind } \\
\text { area. }\end{array}$ \\
\hline 3 & $\begin{array}{l}\text { Pump station for water } \\
\text { intake }\end{array}$ & $\begin{array}{c}15.0 \times 33.0 \\
\text { With varied height } \\
5.7 \mathrm{~m} \text { and } 11.8 \mathrm{~m}\end{array}$ & $\begin{array}{c}18^{\circ} \mathrm{C} \\
\text { heated }\end{array}$ & $\begin{array}{l}\text { Without a cellar, pile foundations and } \\
\text { raft pile foundations. Excavated tank for } \\
\text { water intake }\end{array}$ \\
\hline
\end{tabular}


Evaluation of thermal effect of all listed buildings and structures on frozen soil within the period of construction and maintenance was fulfilled. The planned principle of construction applied to all buildings and structures is preservation of subsoil in frozen state.

\section{Climatic and engineering-geological conditions of the region}

Designed facility is to be built in the northern part of the Yenisei River mouth on its right bank. The territory adjoins to the Tanalau cape. The Tanalau River crosses the area with the designed facility then flows into the Yenisei River to the north of the cape.

The region is characterized by high water saturation mostly with tundra. Soils are typical tundra presented by swampy areas. The topography of the region represents a slightly hilly plain. Height levels range from 0 to 45 meters.

The climate of the region is severe, with low air temperature, high humidity and thick cloudiness. Besides it is characterized by insignificant precipitation and frequent fogs in summer and storms and snowstorms in winter. Average annual air temperature in this area is about minus $11^{\circ} \mathrm{C}$. The warmest month is July, with air temperature from 10.2 to $11.5^{\circ} \mathrm{C}$. The coldest month is January with temperature from minus 28.4 to minus $27.6^{\circ} \mathrm{C}$.

In the northern part of the region ice formation usually starts in the end of the first decade of October, on the rivers - in the end of the second decade of October.

Within the exploration site location, with boreholes drilled up to $40 \mathrm{~m}$ deep, the consequence of layers is the following (from top to bottom):

- modern technogenic deposits;

- modern alluvial deposits;

- Upper Quaternary alluvial deposits

Modern technogenic deposits extend on dry land with artificial sand layer. The deposits are represented by fine sands, coarse, less often by silty sands, light grey, gravel sands, pebble $5-10 \%$ and solid frozen sands. Total thickness of deposits estimates 2.2-3.3 m.

Modern alluvial deposits extend everywhere; underlying technogenic deposits on dry land, in water area - underwater. They are represented by sands, ooze and loam. Clay ooze and loamy silt extend in water area, dark grey, with sand and humus, liquefied and thixotropic. Loams are liquefied, greenish-grey and grey, with interlayers of sand and humus. Sands are silty and fine, dark grey, of medium density, with interlayers of ooze, humus, loam, in water area - water saturated, on dry land - solid frozen. Maximum thickness of modern alluvial deposits estimates $20.7 \mathrm{~m}$.

Upper Quaternary alluvial deposits extend at the base of the exploration site. They are represented by sands and loam. Silty sands, fine, rarely of medium size, medium density, grey, with loam, humus and pebbles, water saturated - in water area, solid frozen - on dry land. Loams are dark grey, with gravel, pebbles and sand; solid, semi-solid - in water area, solid frozen - on dry land. Total thickness of alluvial deposits estimates to $24.6 \mathrm{~m}$.

The exploration site locates in the zone of permafrost's almost entire extension. Thickness of permafrost varies from 10-50 to $450 \mathrm{~m}$. In the river valleys there are taliks of 5-20 m depth, covered with bushes and separate trees.

Significant fluctuations in air temperatures combined with diversity of surface and soils conditions beside ancient deposits formation result in a wide range of average annual soil temperatures.

According to temperature, soils are mostly in solid frozen state and partly in plastic-frozen state in river valleys, small watercourses and swamps.

According to freezing, frozen layer belongs to epigenetic type. Other conditions being equal, regular decrease of ice content which depends on extension depth of permafrost is observed. The upper part of the exploration site (the first $5-10 \mathrm{~m}$ ) is characterized by maximum ice content justified by migration of humidity to the freezing front. 
Ice content and formation of cryogenic rock textures are determined, first of all, by their lithological composition, and within a single type of soil - by genesis. In general, ice content decreases from finely divided rocks to coarse-grained rocks. Clays, loam and sandy loam have maximum ice content $(0.4-0.6 \mathrm{pu})$. They are characterized by layered and reticulate texture, less often ataxitic structure (in case when ice content is more than $0.6 \mathrm{pu}$ - rock becomes an ice bounded unit). Ice content of sands and coarse-grained soils, as a rule, does not exceed $0.03 \mathrm{pu}$, types of cryogenic textures are lump and crust respectively. Peat has high ice content (0.2-0.4 pu), and layered or reticulate cryogenic textures.

Frozen soils underlie seasonally thawed layer or adjoin permafrost taliks. Thickness of active layer and talik areas depends on meteorological factors, snow thickness, season, geomorphological position and types of soils. In open spaces devoid of vegetation, with sand and sandy loam, depth of seasonally thawed layer estimates maximum 2.0-2.5 m, in swampy areas $-0.1-0.3 \mathrm{~m}$.

\section{Temperature modeling of permafrost conditions}

Temperature calculations covered the entire period of buildings and structures existence, i.e. 50 -year period. Thus, one step covered 1 year, and therefore calculation provided 50 steps. Besides to assess monthly changes in soil temperature, calculations for shorter time intervals (1-2 years) were performed when one step covered 1 month.

The results of calculation are presented in the form of outlined zones of thawed and frozen soils. These zones are shown in Fig. 1 in different colors (frozen soil in blue color). The "0 ${ }^{\circ} \mathrm{C} "$ isotherms were accepted as thawing zones boundaries. If thawing zone boundary did not exceed the depth of seasonal soil thawing the design solution was considered acceptable. Calculation results regarding administration building are shown in Fig. 2.

In long-term calculations predicted global climate change - air temperature raises to around $0.4{ }^{\circ} \mathrm{C}$ within 10 years - was taken into account. Subsoil temperature, being constant at a certain depth, corresponds to subsoil temperature in April (of minus $4{ }^{\circ} \mathrm{C}$ on average) was taken as initial condition in all calculations.

All calculations were performed with certified software package "FEM models", which includes software module "Termoground", designed for freezing and thawing soils calculation.

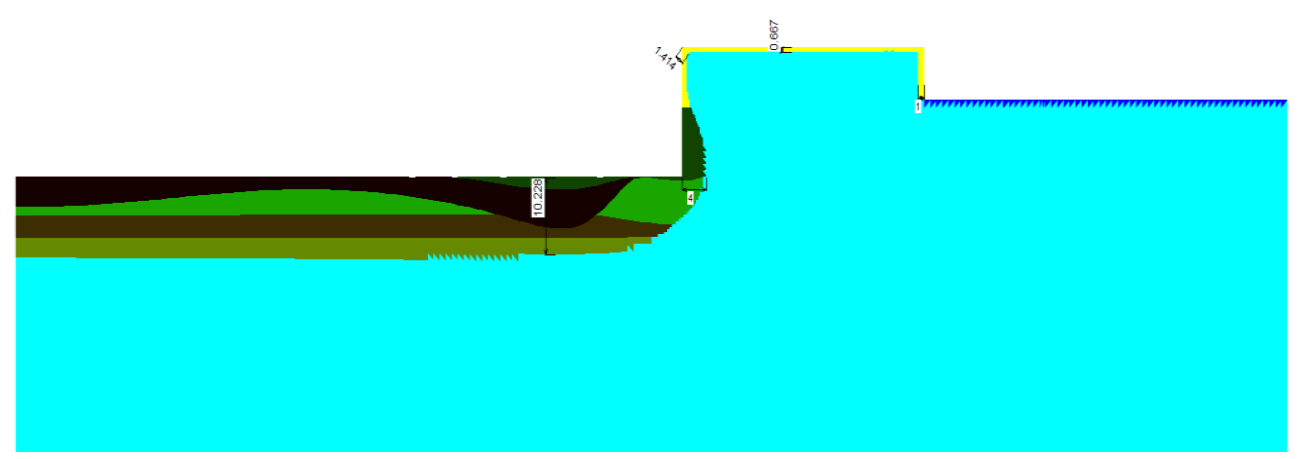

Fig. 1. Oil-loading river pier. Thawing and frozen soil zones (thawing up to $0{ }^{\circ} \mathrm{C}$ ). Initial soil temperature is minus $2^{\circ} \mathrm{C}$. 


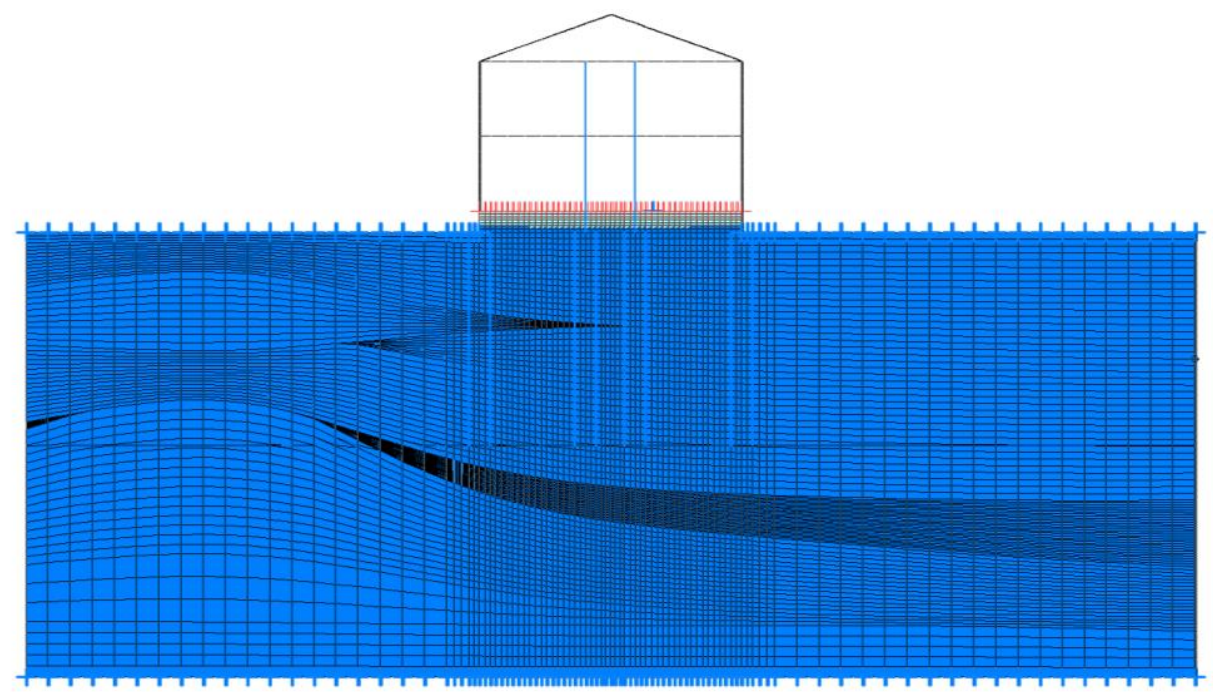

Fig. 2. 50 years later, thawing zone under administrative building is not formed. Boundary temperature is $0{ }^{\circ} \mathrm{C}$.

\section{Conclusions}

1. Modern numerical models $[1,2]$ for "structure - frozen soil" system's complex calculation permits to solve compound technical tasks to provide stability to buildings and structures of any purpose in transport infrastructure, in the Arctic region conditions.

2. The "Termoground" software [1,3] has been tested in real facilities with long-term monitoring data on stability and deformation in various transport structures both in conditions of deep seasonal freezing and deep-frozen soil.

3. Federal Act No. 384-RF "Technical Regulations to provide Buildings and Structures' Security" being introduced, numerical calculation has become a necessity to meet the requirements on transport systems mechanical security since 2010. The developed "Termoground" software gives an opportunity to solve transport problems of any complication and provides security in constructing on frozen soils, considering temperature changes in terms of possible global climate warming.

4. As a result, it was detected that depth of thawing under water area will reach $10.2 \mathrm{~m}$ in 50 years of oil-loading pier's maintenance, and width of thawing towards the bank - up to $4 \mathrm{~m}$. If freezing temperature (minus $0.7^{\circ} \mathrm{C}$ ) is taken as soil thawing boundary temperature, then depth of thawing under water area will reach $12.4 \mathrm{~m}$, and width of thawing towards the bank - up to $5 \mathrm{~m}$. It is revealed that $75-80 \%$ of thawing width behind the front wall is formed during the first 10 years, and then it increases slowly. Thawing under water area occurs during the entire 50 -year period of maintenance.

5. As to bank retaining walls, depth of seasonal soil thawing up to $0{ }^{\circ} \mathrm{C}$ will reach maximum $1,2 \mathrm{~m}$; by slopes edge, due to bilateral freezing, - about $2.4 \mathrm{~m}$. If freezing temperature (minus $0.7^{\circ} \mathrm{C}$ ) is taken as soil thawing boundary temperature, then depth of seasonal soil thawing will not change fundamentally in comparison to thawing up to $0{ }^{\circ} \mathrm{C}$.

6. Calculations show that in 50 years after administrative building's maintenance there will be no soil thawing, since ventilated cellar permits subsoil to remain in frozen state. Seasonal thawing depth of embankment next to the building will estimate $0.9 \mathrm{~m}$. 
7. Depth of thawing under building for technical purposes to store special equipment will reach the lowest boundary of thermal insulation layer in 50 years of its maintenance. Depth of seasonal thawing of embankment next to the building will be about $1 \mathrm{~m}$.

8. Peculiarity of pumping station for water intake is presence of a water tank. According to calculations, done for 50 years ahead, subsoil thawing zone under the building will not be formed. However, subsoil thawing zone around the tank will be formed due to positive water temperatures, which is taken from The Yenisei River. Calculations show that soil thawing boundary around the tank will extend outward maximum to $3.6 \mathrm{~m}$. Since the distance between the tank edge and the lateral surface of the nearest pile estimates $5.35 \mathrm{~m}$, it can be assumed that the piles will not get into the soil thawing zone.

\section{References}

1. S. Kudryavtsev, I. Sakharov, V. Paramonov, Freezing and thawing of the soil (practical examples and finite element calculations) (Georeconstruction, St. Petersburg, 2014)

2. V.N. Paramonov, I.I. Sakharov, Proceedings 5-th Int. Geotechnical Symposium, Geotechnical Engineering for Disaster Prevention and Reduction IGH5, 122-127 (2013)

3. S.A. Kudryavtsev, V.N. Paramonov, V.M. Ulitskii, I.I. Sakharov, Journal Soil Mechanics and Foundation Engineering 52(5), 240-246 (2015) 